\title{
Training managers to facilitate their meetings: an intervention study
}

\author{
Ib Ravn \\ Department of Education, \\ Aarhus University, \\ Tuborgvej 164, 2400 Copenhagen, Denmark \\ Email:ravn@dpu.dk
}

\begin{abstract}
Meetings in organisations are a common object of popular frustration. They are often run by managers who picked up their meeting skills from their superiors a generation previously, thus perpetuating obsolescent practices unsuited to today's world of work. This paper reports on a research-based intervention effort to improve organisational meetings. It reconceptualises classical meeting management, offering instead the practice of 'meeting facilitation': a more active and supportive approach, in which the manager-as-facilitator guides and directs conversations in meetings towards a positive goal. To test this reconceptualisation in a live experiment intended to improve real meetings, we conducted brief training of 103 managers in meeting facilitation in two organisations in Denmark. A pre- and post-intervention survey of a thousand employees who regularly participated in these managers' meetings showed that in the employees' judgement, there were significant improvements in their managers' competencies in both new meeting facilitation and classical meeting management, whereas other meeting outcomes resisted change.
\end{abstract}

Keywords: meeting; organisational meetings; meeting management; group facilitation; meeting facilitation; competency development; management development; management training; management practice; design-based research; transformative research; intervention; Denmark.

Reference to this paper should be made as follows: Ravn, I. (2014) 'Training managers to facilitate their meetings: an intervention study', Int. J. Management Practice, Vol. 7, No. 1, pp.70-87.

Biographical notes: $\mathrm{Ib}$ Ravn received his $\mathrm{PhD}$ from the University of Pennsylvania's Wharton School of Business. He heads the research group 'Facilitating Knowledge Processes' in Aarhus University's research programme on organisation and learning. He does research on knowledge sharing and its facilitation in meetings, conferences, networks and face-to-face in organisations generally, and he consults to private and public sector organisations in Denmark and abroad. He has published six books on science and society and on facilitation, amongst them 'Learning Meetings and Conferences in Practice' (with Steen Elsborg, People's Press, 2007). Before rejoining academia in 2002 he worked for 13 years in the private sector as a consultant and a publisher. 


\section{Meetings: maligned by practitioners, ignored by academics}

Meetings are ubiquitous in modern organisations. Everyone knows tedious and ineffective meetings from personal experience or anecdote, and research bears this out: meetings are time-consuming (Mintzberg, 1973), often detract from job satisfaction (Rogelberg et al., 2010) and are regularly unproductive and wasteful (Romano and Nunamaker, 2001, p.11). Meetings hold tremendous potential for improvement.

Typically, responsibility for the conduct of a meeting rests with the leader of the group attending the meeting (of course, many a meeting has no such obvious leader; another person may or may not step in to chair it). To a large extent, the success or failure of a meeting is a reflection of this leader's meeting skills.

Few managers have received formal training in meeting management. Widely considered a low-level, operational skill, it is not included in the scholarly ambitious business school curriculum, whether at undergraduate, MBA or executive education levels. At the same time, it is generally not taught in vocational schools, either; presumably because it is a management skill, and managers, of course, are trained in business schools.

Thus orphaned, meeting management is something that most managers are left to learn by experience, emulating their elders with little reflection or critique. We can safely assume that managers often perpetuate meeting forms and procedures which, because they remain unexamined, are of diminishing relevance to a business environment increasingly different from that of their role models.

There is an extensive how-to literature on meeting skills of the conventional kind, where the emphasis is on agenda use and decision making at meetings; that is, on dealing with meeting content (e.g. Henkel, 2007; Streibel, 2002). Of interest in the present paper is another approach to handling meetings: group facilitation. "Facilitation is about process - how you do something - rather than content - what you do" (Hunter, 2007, p.19). A facilitator is an alert and active group leader who guides, supports and controls the flow of the meeting, with a view to better engaging meeting participants and creating results efficiently.

This paper reports results from an intervention study in Denmark, the purpose of which was to create improvement in meetings by providing middle managers with brief training in group facilitation. The study involved two organisations: a government agency and a bank, each of which received an intervention, framed as competency development of 50 managers/supervisors in each organisation. The intervention involved training workshops, coaching and redesign of meeting formats. ${ }^{1}$ In order to assess the efficacy of the intervention, it was preceded, as well as followed, by measurements of meeting participants' estimates of their managers' skills and the meeting processes used.

As we shall show, it seems possible for managers, after engaging with group facilitation techniques appropriate to meetings for only 1-2 days, to develop their meeting leadership competencies significantly and improve critical meeting parameters.

\section{Reconceptualisation: from chairperson to meeting facilitator}

In many Western organisations, meetings are conducted in a manner that draws on two traditions (Hunter, 2009, p.22; Garon, 2002, p.215): 
1 One is the authoritarian style known from hierarchical and paternalistic organisational cultures, where the patriarch controls the content of meetings, keeps the floor largely to himself and calls on others to contribute as he sees fit.

2 The other is the parliamentary style, in which a chairperson regulates deliberations in a democratic assembly or committee according to a set of impartial, detailed procedures (cf. Robert's Rules of Order, 1915/2008). Well-known elements of this style include everyone's right to speak, raising your hand to indicate your wish to speak, no interrupting another speaker, keeping a speaker's list, proposing motions, and taking votes.

'Chairing a meeting' is the common, but slightly formal term for running a meeting (its first use was recorded by the Oxford English Dictionary as late as 1921). In recent years this has also came to be known as meeting management (Smith, 2000), which term we shall adopt here.

Practically, every office worker with a few years' experience knows the basics of meeting management. It involves preparing an agenda, calling the meeting well in advance, inviting the right people, starting on time, walking the group through the agenda, giving orientation and chairing discussions, maintaining a speaker's list, wrapping things up, finishing on time and making sure the minutes are written and distributed promptly.

These various responsibilities of the chairman or meeting manager may be summarised under the three headings: (a) basic time management, (b) agenda use, and (c) ensuring results (cf. Figure 1).

This widespread familiarity with the time-worn principles of how to run a meeting co-exists in the popular mind with a more realistic or even cynical view of meetings. This view is rarely articulated, is difficult to tease out and may not be easily confirmed, since people are unlikely to agree that they actually hold it. This tacit view of meetings, which may be called a folk theory of meetings, was identified from interviews taken during the research project from which this paper reports quantitative data (Ravn, 2013).

The folk theory of meetings can be expressed in terms of six assumptions (Table 1).

Table 1 The six assumptions of the folk theory of meetings (from Ravn, 2013)

\begin{tabular}{lll}
\hline \multicolumn{2}{c}{ Folk assumption } & \multicolumn{1}{c}{ Explained } \\
\hline $\begin{array}{l}\text { Meetings will } \\
\text { be meetings }\end{array}$ & $\begin{array}{l}\text { If you work in an office, you go to meetings occasionally. Some } \\
\text { are good, some are bad. That's just the way it is. You put up with } \\
\text { them or try to stay away. }\end{array}$ \\
\hline 2 & $\begin{array}{l}\text { The agenda is of } \\
\text { prime importance }\end{array}$ & $\begin{array}{l}\text { A meeting flounders without an agenda. If only we have a good } \\
\text { agenda, our meeting will be alright. }\end{array}$ \\
\hline 3 & $\begin{array}{l}\text { The chairperson } \\
\text { executes the meeting }\end{array}$ & $\begin{array}{l}\text { Pun intended. Chairing a meeting is running through a standard set } \\
\text { of formal rituals. Not exciting and not expected to be. }\end{array}$ \\
\hline & $\begin{array}{l}\text { The leader may speak } \\
\text { as much as he pleases }\end{array}$ & $\begin{array}{l}\text { When managers are chairpersons, they own the meeting and may } \\
\text { speak at length to any and all points on the agenda. }\end{array}$ \\
\hline & $\begin{array}{l}\text { Meetings are where } \\
\text { we discuss things }\end{array}$ & $\begin{array}{l}\text { Free-for-all discussions are the standard fare of meetings. Next to } \\
\text { management orientation, this is what happens at meetings: we } \\
\text { speak our minds. }\end{array}$ \\
\hline
\end{tabular}


Put in terms as stark as these, meetings conducted in the traditional way should give us pause. Can they be revitalised using the classical means of authoritarian-cumparliamentary chairmanship? Or would we be well advised to look for alternatives?

We may need to see meetings afresh and reconceptualise the manner in which they are run. Group facilitation has been identified as a suitable alternative to classical chairmanship (Doyle and Straus, 1976; Ravn, 2011). It is a style of process leadership and a set of dynamic techniques used mostly in workshops and other stand-alone events (Schwarz, 1994), not normally in ordinary meetings. In such workshops, hired facilitators or process consultants (Schein, 1988) help executives, decision-makers or stakeholders share information, develop new ideas and reach common understandings. Being seen as neutral to the content of the discussions, facilitators control their form in an attempt to help the group produce desired outcomes.

Facilitators guide the flow of communication, eliciting input from some and keeping others back; they divide a large group into pairs or small groups to mull things over and cherry-pick from them in the large group afterwards. They work hard to keep people engaged and ensure productivity - by other and more subtle means that just nodding and letting the next speaker on the list take her turn.

Group facilitation is widely used in management consulting (Bens, 2002), learning and education (Rogers, 1967), community development (Schuman, 2005) and crosscultural work (Hogan, 2007). Facilitation enjoyed academic interest mostly in the 1990s, when electronic group support systems were much in vogue, since a facilitator was needed to operate the equipment and guide the conversation in the different locations hooked up (Bostrom et al., 1993).

Many writers, notably and very early Doyle and Straus (1976), have adapted the consultant's large-group facilitation approach for use in the everyday and often small meetings in organisations. This requires that the leader of the assembled group or some other person takes on the very active role of facilitator and helps guide the meeting through its deliberations.

Among the many facilitator characteristics, competencies and functions mentioned in the literature (Hogan, 2003), which are relevant in the context of the bread-and-butter organisational meeting? To answer this question, let us find guidance in the folk theory of meetings. Two concerns stand out.

1 One relates to the last three assumptions presented in Table 1 and is about who speaks at meetings and who does not. Assumptions 4-6 may be phrased as 'The leader talks too much', 'The domineering group members talk too much' and 'The others don't contribute'. A commonly recognised facilitator responsibility is to engage participants more equally and more productively in the meeting than is possible through the standing invitation to chip in, because that typically enables dominant members to monopolise the floor. We call this concern Engaging participants.

2 The second concern that appears from the folk theory is the popular emphasis on the agenda and its execution, as if the agenda ensures focused discussions and proper meeting outcomes. However, by itself, the agenda does not do this. If a discussion strays off-topic, who gets it back on track? An authoritarian-type chairperson does not allow much discussion to begin with, but if he strays, there is no one to hold him back. A parliamentary-democratic-type chairperson lets the next speaker on the list talk, meekly hoping she will stay on track, and in the process he becomes a meeting 
follower rather than meeting leader. A facilitator, in contrast, helps everyone remain focused by actively intervening and stopping side tracks, politely but firmly. Also, she takes charge redefining the focus of the group's deliberations if topics not on the agenda require attention before topics on the agenda can be settled. We call this concern Maintaining focus and direction.

For a summary of the ways meetings can be conducted and the skills it takes, please refer to Figure 1.

Figure 1 Origins of meeting management, its contrast to group facilitation, and their merger in meeting facilitation

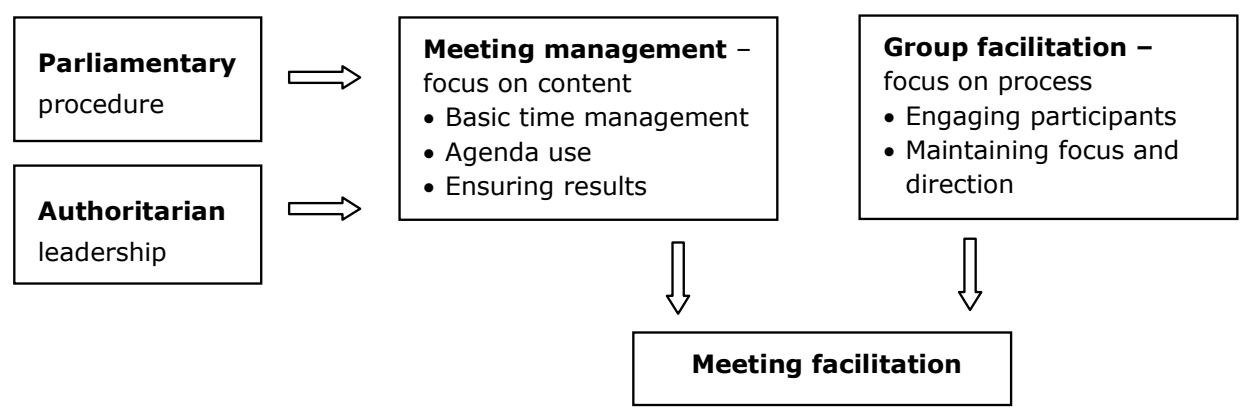

\section{Design: requisite meeting facilitator competencies}

The two concerns engaging participants and maintaining focus and direction are core facilitator competencies to be mastered by meeting managers if they want to counter the folk theory and seek to improve meetings - and thus reject the remaining folk assumption, no. 1, the bleak notion that meetings will be meetings.

The idea that for meetings to improve meeting managers must acquire these additional skills lies behind the research-and-development project reported here. Changeoriented research efforts in organisations and the educational system have similarly started from an idea of what the change should lead to, variously termed a design (Barab and Squire, 2004; van Aken and Romme, 2009), a futures theory (Baburoglu and Ravn, 1992) or a transformative theory (Ravn, 2005). In so far as we are justified in calling this view of meetings (which states that efficient and engaging meetings are facilitated, not just chaired in the conventional way) a theory, the present intervention effort can be said to be theory-driven.

Now, using the design terminology of Denyer et al. (2008), design propositions specify the design, and generative mechanisms are the particular kinds of actions that need to be taken to implement the design. Thus,

1 The design, motivated by the research that went into articulating the folk theory of meetings (Ravn, 2013), is the idea that chairpersons or meeting managers are at loss in contemporary meetings and they need to complement their traditional skills (basic time management, agenda use, and ensuring results) with some of the modern tools of group facilitation, 
2 The design propositions are the two specific facilitator concerns: engaging participants and maintaining focus and direction, that the folk theory of meetings led us to identify, and

3 The generative mechanisms are specific facilitator techniques which when applied in a new style of meeting leadership that we refer to as meeting facilitation will lead to more effective and engaging meetings.

To implement and test this design, we decided against common experimental formats, such as asking groups of volunteers to participate in meetings facilitated by expert facilitators, whether in the lab (in the vein of much psychological experimentation) or in real life, as is common in intervention projects in workplace development and redesign (Kristensen, 2005). In both cases, once the expert facilitator leaves the scene, and in the absence of someone taking over, meetings will most likely deteriorate to previous levels, no matter how well they responded to 'treatment'. Obviously, meeting participants and leaders do not need to be given a fish, but to learn how to fish. This thinking follows the recent turn in organisational development and firm strategy towards a competence-based view (Heene and Sanchez, 1997; Freiling et al., 2008): the skills and competences held by managers and organisational members matter as much as the resources at the organisation's disposal.

Consequently, we devised a training-and-development programme that was implemented in two organisations, each of which had front line managers interested in learning group facilitation skills, to complement their classical meeting management skills.

As indicated, we assumed managers already possessed meeting management skills, but we wanted to assess the extent of their knowledge. Thus, we further broke down the meeting manager's three core competencies thus:

Meeting management (focus on content)

A Basic time management

1 Starting the meeting on time

2 Finishing it on time

B Agenda use

3 Preparing an agenda and

4 Ensuring the meeting gets through it

C Ensuring results: Formulating...

5 Conclusions to every agenda item and

6 'Action points' after entire meeting

As we shall see below, these six specific competencies will appear as items in a questionnaire that assesses the degree to which each competency is held by the managers that entered the brief training programme.

The training focused on group facilitation competencies, each of which was identified by breaking down the two concerns mentioned thus: 
Group facilitation (focus on process)

\section{Engaging participants}

7 Reading the mood of the meeting and building the trust necessary for everyone to participate

8 Including everyone by being attentive to their needs to be listened to and taken seriously

9 Using round-robins, dyads and small-group activities to give everyone a voice at the meeting

E Maintaining focus and direction during discussions

10 Making sure that everyone knows not only what is to be discussed (which is what a conventional agenda tells us), but also what needs to be accomplished through that discussion

11 Keeping the conversation constructive and directed towards what needs to be accomplished

12 Dealing effectively with emerging topics and tangents that threaten to derail the discussion.

Items 7-12 also went into the questionnaire and were used for before- and aftermeasurements to assess the efficacy of the training.

As will appear below, the group facilitator competencies picture the facilitator as more actively guiding and supporting the conversation at the meeting than a conventional chairperson, who, during group discussions, is tempted to simply give the floor to the next person indicating. As is sometimes seen in meetings, a chairperson may be somewhat disengaged from the proceedings, being content with simply letting the next person speak, while a group facilitator is extremely attentive, monitoring the back-andforth very closely, helping the discussion move in the right direction.

Combining the skills of the meeting manager with those of the group facilitator, we arrive at a 'meeting facilitator' (see Figure 1), a species of meeting leader that we conjecture is better equipped for modern meetings. As we assumed that managers were already sufficiently skilled at the well-known meeting management competencies in A-C, the design to be tested in the intervention involved the group facilitator's competencies, those under D-E, nos. 7-12. They constitute the generative mechanisms (Denyer et al., 2008) that must be implemented in practice and through which the design is hypothesised to lead to improvements in meeting outcomes.

The reasoning behind the project is summarised in Figure 2. To improve meetings, we need better meeting leadership. This requires competencies in group facilitation, to be obtained through training (the arrows indicate the hypothesised direction of causality).

Figure 2 What is required for better (that is, more effective and engaging) meetings






\section{Hypotheses about meetings and facilitation}

The ideas to be tested may be summarised as follows (MM stands for the questionnairederived measure (see below) of meeting management and GF for that of group facilitation.)

First of all, the training in group facilitation should lead to better group facilitation:

Hypothesis 1: After the intervention phase, the managers' group facilitation competencies are better than they were before: $G F_{\text {after }}>G F_{\text {before }}$.

(GF is the questionnaire-derived measure of group facilitation, as assessed by each leader's meeting participants: the items nos. 7-12 from above, as operationalised in the questionnaire, see below).

Since the intervention does not train meeting management competencies, we do not expect them to improve:

Hypothesis 2: After the intervention phase, the managers' meeting management competencies are no different from what they were before: $M M_{\text {after }}=M M_{\text {before }}$.

As we have defined meeting facilitation to be the combination of meeting management and group facilitation (or in terms of scores: their weighted sum, that is: $M M+G F=M F$ ), we expect it to improve after the intervention:

Hypothesis 3: After the intervention phase, managers' meeting facilitation competencies are better than they were before: $M F_{\text {after }}>M F_{\text {before }}$.

Specifically, we wish to investigate some core issues in meeting management and group facilitation by comparing pairs of variables (questionnaire items) before and after the intervention. These issues are addressed by the three hypotheses, nos. 4-6, that follow.

A traditional agenda is a list of topics (typically presented as nouns) to be discussed, but it is not clear from the agenda what the desired type of outcome is for each agenda item (despite the Latin root of 'agenda': '(things) to be done'). This does nothing to help participants make relevant contributions to the discussion. Although a good meeting manager will open the floor by stating the purpose of the discussion, this is often too late: participants articulate whatever associations formed in their minds when they first glanced upon the agenda item. This contributes to the excessive talk and lack of focus known from many meetings.

A facilitator's trick for addressing this is to add a line of text to each agenda item specifying in everyday language what needs to be accomplished. Thus, if the agenda item would normally appear as 'Project X, update', this helpful text would be added: 'We need to decide whether to go into phase 4 of project $X$ and who will try to secure the funding for it'. This change in agenda composition was part of the training.

Hypothesis 4a: Before the intervention phase, meeting participants are better informed about what is to be discussed at the meeting (= there is an agenda) than what needs to be accomplished at the meeting.

Hypothesis 4b: After the intervention phase, this gap is reduced (meaning that participants are now better informed as to what needs to be accomplished at the meeting). 
It is a pillar of meeting management that a good meeting covers all the items on the agenda (Rogelberg et al., 2007, p.21). The eager meeting manager will rush to do just this, sometimes leaving items hanging in mid-air, with meeting participants being unclear as to what was actually the outcome of a particular discussion. This gap between just discussing things at meetings and actually accomplishing something at meetings is part of the rationale for the present intervention, but since a classical meeting manager well knows what to do about it - viz., adequately wrapping up each agenda item before moving on to the next one - it was not part of the training (although in retrospect, perhaps it should have been). Hence, we examine two hypotheses, one about how things are and one about what changes we can expect after our intervention:

Hypothesis 5a: Before the intervention phase, meeting participants experience more meetings that cover the entire agenda than meetings where each agenda item is properly wrapped up.

Hypothesis 5b: Since this gap (between merely covering the agenda and ensuring that each item is properly wrapped up) was not addressed in the training given in the intervention phase, it is not reduced, that is, there is no improvement.

A major reason for many people's disenchantment with meetings is their own lack of involvement in them (Romana and Nunamaker, 2001, p.6). Extroverts and meeting participants that are better positioned than others will speak often and freely, whereas introverted, inexperienced or indifferent group members will remain quiet. A traditional meeting manager will sense this and occasionally ask a silent participant: "Well, George, you've been awfully quiet. What do you think about all this?" Of course, this wellmeaning attempt to include George often comes across like an ambush and may indeed embarrass quiet meeting participants who cannot summon a suitable opinion on such short notice.

A group facilitator will involve everyone by breaking up the plenary discussion forum that is the root cause of disengagement: many people vying for one microphone, so to speak (Hogan, 2003). This may be done in various ways:

- Two minutes of silent reflection in the middle of a meeting, which allows introverts to collect their thoughts;

- Breaking people into buzz dyads ('pair-and-share') that discuss a crucial meeting topic for five or ten minutes;

- A flash round robin that gives everybody a minute to contribute their thoughts while all the others listen, or

- Five minutes of facilitator cherry-picking if the meeting is too large for everyone to speak (Elsborg and Ravn, 2007).

Processes like these were included in the training and were expected to increase the sense of involvement experienced by meeting participants. Hence:

Hypothesis 6a: After the intervention phase, meeting leaders use more involvementinducing processes than they did before.

Hypothesis 6b: After the intervention phase, meeting participants feel more involved than they did before. 


\section{Methods: intervention and pre- and post-measurements}

To test these hypotheses, three Danish organisations interested in improving their meetings were recruited, first by email solicitation from a list of the 50 largest Danish companies and, when that proved only partially successful, through personal contacts. They were a large department of municipal government, a government agency and a bank.

In each organisation, top management and/or the HR department invited or handpicked fifty managers/supervisors, most of whom were in charge of personnel groups or offices of 5-20 employees. They took part in the intervention, which took place over an eight-month period, and they and their subordinates agreed to pre- and post-intervention data collection, over two five-month periods. One organisation dropped out of the project before the post-intervention measurement, leaving two organisations to report data from: the agency and the bank.

The intervention was divided into three parts:

1 Two full-day workshops separated by a two-month interval held on each organisation's premises. Each workshop was split in two to obtain a suitable learning-group size of about 25. Participants were introduced to group facilitation techniques and practiced them repeatedly in small-group exercises that addressed real-world challenges culled from their everyday meetings. The 'curriculum' was as specified in the list of group facilitation competencies 7-12 above: reading mood and building trust, inclusiveness through active listening, participatory processes, use of a 'what's-to-be-accomplished' agenda format, techniques for constructive dialoguing, and practice in interrupting tangents politely and effectively.

2 One coaching session for each manager, $75 \mathrm{~min}$, where they pursued self-identified challenges relating to meeting facilitation.

3 A redesign of 2-3 meeting types prominent in each organisation. In the bank, the redesign involved the quarterly management group meeting (attended by all 50 managers) and the weekly staff meeting (attended by $5-15$ people); in the agency it was the weekly office meeting (10-20 people), the ad-hoc project group meeting (5-10 people) and the weekly meeting of department heads (20 people).

While the training workshops and the coaching sessions were conducted by the project team (the author and the two associates previously acknowledged), the redesigns were a collaborative effort between us and representatives from the organisations. The resultant meeting redesigns were subsequently communicated to and implemented in the respective organisations through mentoring (in the bank) and an additional full-day workshop for a new group of employees: non-managerial project leaders (in the agency).

To assess the efficacy of the intervention, data about meetings and how they were conducted in the two organisations were collected. So as to move beyond the satisfaction scores obtained by querying the managers who took part in the intervention programme ('How satisfied were you with today's training?'), which corresponds to the rudimentary level 1 in Kirkpatrick and Kirkpatrick's (2006) outcome-of-training typology, we 
surveyed the employees who attend the everyday meetings run by the managers in question, as this would yield results that correspond to the more demanding level 3 in the Kirkpatrick typology, changed behaviour, and level 4, results.

Meeting participants (survey respondents) were defined and identified organisationally by their membership of the office or department headed by each manager. As these employees attend other meetings as well, in the survey they were asked specifically to think about their department manager and the meetings they go to with him/her.

The 12 competencies in the meeting management (MM) and group facilitation (GF) dimensions were operationalised into as many questionnaire items, phrased in a simpler manner. For example, item 7 is 'How good is your meeting leader at reading the mood of the meeting and ensuring that everyone feels comfortable?', and item 10 is 'By the start of the meeting, is it clear what you all need to accomplish at the meeting - beyond talking about some things?'

A Likert scale was employed, with ' 3 ' as the neutral midpoint and ' 1 ' the low extreme and ' 5 ' the high extreme. For rigour, the extremes were given the more demanding label 'to a particularly low/high degree', rather than the conventional 'to a very low/high degree', so as to distinguish these response categories clearly from ' 2 ' and '4', 'to a low degree' and 'to a high degree'. In retrospect, this choice may have been unwise, possibly causing the responses to tend away from the extremes.

Temporal questions were given suitable response categories indicating number of minutes or frequency.

Three additional questionnaire items were included (see Table 7) for descriptive purposes. Here, respondents were asked to think of all meetings attended, not just those with their own manager. Hence, these variables are unlikely to be affected much by the training, since organisational members usually go to many meetings besides those with their managers, and thus only pre-intervention results are given.

\section{Results: post-intervention changes in meeting leadership}

The survey was administered using Inquisite, an electronic survey programme. This produced satisfactory response rates of $66 \%$ and $60 \%$ in the pre- and post-intervention surveys, respectively (see data in Table 2). Results were analysed in SPSS using Student's independent samples t-test for the hypotheses. A significance level of $p \leq 0.05$ is indicated by '*', $p \leq 0.01$ by '**' and $p \leq 0.001$ by ' $* * *$ '. (In the agency, a fair number of managers who signed up for the training did not actually show up, so their employees came to constitute a control group, although not entirely randomised. Thus, for the agency, the data reported for hypotheses are the differences between the control group and the treatment group.)

Table 2 Survey administration data

\begin{tabular}{lccc}
\hline \multicolumn{1}{c}{ Survey } & $\begin{array}{c}\text { Bank and agency employees } \\
\text { receiving survey, } N\end{array}$ & Responses, $n$ & Response rate \\
\hline Before the intervention & 1081 & 715 & $66 \%$ \\
After the intervention & 1053 & 637 & $60 \%$ \\
\hline
\end{tabular}


Table 3 presents data on the three main hypotheses $1-3$. Tables $4-6$ address hypotheses 4-6 regarding agenda use and involvement of meeting participants. Finally, Table 7 presents additional data on meetings: number of meetings per week, time spent in meetings and time perceived to be wasted.

Table 3 Data for hypotheses 1-3 on group facilitation (GF), meeting management (MM) and meeting facilitation $(\mathrm{MF})$ (Note that $\mathrm{MF}=\mathrm{MM}+\mathrm{GF})$

\begin{tabular}{|c|c|c|c|c|c|}
\hline $\begin{array}{l}\text { Hypo- } \\
\text { thesis no. }\end{array}$ & Hypotheses & \multicolumn{2}{|c|}{$\begin{array}{l}\text { Variables, and scores } \\
\text { on Likert scale } 1 \text { to } 5 \\
\text { (5 is best) }\end{array}$} & Difference & $\begin{array}{l}\text { Hypothesis } \\
\text { confirmed? }\end{array}$ \\
\hline 1 & $\begin{array}{l}\text { After the intervention, the } \\
\text { managers are better at Group } \\
\text { Facilitation (GF) than they } \\
\text { were before }\end{array}$ & $\begin{array}{c}\text { GF before: } \\
3.22\end{array}$ & $\begin{array}{c}\text { GF after: } \\
3.38\end{array}$ & $0.16^{* * *}$ & Confirmed \\
\hline 2 & $\begin{array}{l}\text { After the intervention, } \\
\text { managers are no better at } \\
\text { Meeting Management }(\mathrm{MM}) \\
\text { than they were before }\end{array}$ & $\begin{array}{c}\text { MM before: } \\
3.52\end{array}$ & $\begin{array}{c}\text { MM after: } \\
3.66\end{array}$ & $0.14 * * *$ & Rejected \\
\hline 3 & $\begin{array}{l}\text { After the intervention, } \\
\text { managers are better at } \\
\text { Meeting Facilitation (MF) } \\
\text { than they were before }\end{array}$ & $\begin{array}{l}\text { MF before: } \\
6.74 \\
(/ 2=3.37)\end{array}$ & $\begin{array}{l}\text { MF after: } \\
7.04 \\
(/ 2=3.52)\end{array}$ & $\begin{array}{c}0.30 * * * \\
(/ 2=0.15)\end{array}$ & Confirmed \\
\hline
\end{tabular}

Table 4 Data for hypothesis 4 on what is to be discussed vs. what is accomplished in meetings (' $4+5$ ' is the percentage of the respondents scoring in the ' 4 ' or ' 5 ' response categories)

\begin{tabular}{|c|c|c|c|c|c|c|c|}
\hline \multirow[t]{2}{*}{$\begin{array}{c}\text { Hypotheses } 4 a \\
\text { and } 4 b\end{array}$} & \multicolumn{2}{|c|}{$\begin{array}{l}\text { Degree to which } \\
\text { respondents } \\
\text { know what is } \\
\text { to be discussed } \\
\text { at meeting }\end{array}$} & \multicolumn{2}{|c|}{$\begin{array}{l}\text { Degree to which } \\
\text { respondents know } \\
\text { what is to be } \\
\text { accomplished through } \\
\text { that discussion }\end{array}$} & \multirow[t]{2}{*}{$\begin{array}{l}\text { One-sample } \\
\text { difference } \\
\text { and } p\end{array}$} & \multirow[t]{2}{*}{ Hypotheses } & \multirow[t]{2}{*}{ Result } \\
\hline & Score & $4+5$ & Score & $4+5$ & & & \\
\hline Before & 3.62 & 60 & 3.09 & 29 & $0.51 * * *$ & $\begin{array}{l}\text { 4a: Merely } \\
\text { knowing } \\
\text { what is to be } \\
\text { discussed is } \\
\text { not the same as } \\
\text { knowing what } \\
\text { to accomplish } \\
\text { during the } \\
\text { meeting }\end{array}$ & S Confirmed \\
\hline $\begin{array}{c}\text { Before/after } \\
\text { difference }\end{array}$ & 0.05 & & $0.14 * * *$ & & 0.06 & $\begin{array}{l}\text { 4b: This gap will } \\
\text { be reduced } \\
\text { through the } \\
\text { intervention }\end{array}$ & $\begin{array}{l}\text { Rejected } \\
\text { (the gap } \\
\text { was not } \\
\text { reduced) }\end{array}$ \\
\hline
\end{tabular}


Table 5 Data for hypothesis 5 on covering the agenda vs. wrapping up agenda items properly

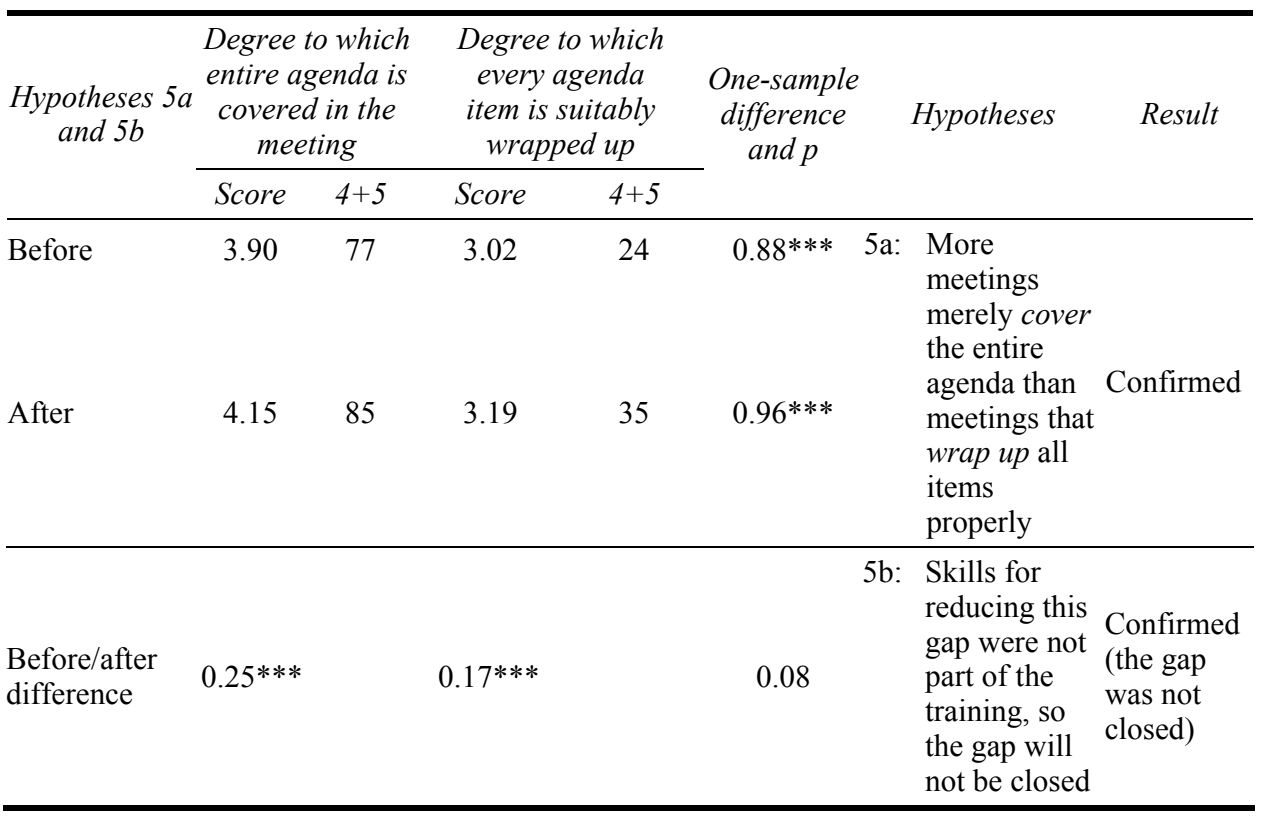

Table 6 Data for hypothesis 6 on the use of involvement-inducing processes and the participants' experience of having been included

\begin{tabular}{|c|c|c|c|c|c|c|c|c|}
\hline \multirow{2}{*}{$\begin{array}{c}\text { Hypotheses } 6 a \\
\text { and } 6 b\end{array}$} & \multicolumn{2}{|c|}{ Before } & \multicolumn{2}{|c|}{ After } & \multirow{2}{*}{\multicolumn{2}{|c|}{$\begin{array}{l}\text { Difference } \\
\quad \text { and } p\end{array}$}} & \multirow{2}{*}{ Hypotheses } & \multirow{2}{*}{ Result } \\
\hline & Score & $4+5$ & Score & $4+5$ & & & & \\
\hline $\begin{array}{l}\text { Degree to } \\
\text { which } \\
\text { facilitator uses } \\
\text { involvement- } \\
\text { inducing } \\
\text { processes }\end{array}$ & 2.03 & 7 & 2.41 & 15 & $0.38 * * *$ & 6a: & $\begin{array}{l}\text { After the } \\
\text { intervention, } \\
\text { meeting } \\
\text { leaders use } \\
\text { more } \\
\text { involvement- } \\
\text { inducing } \\
\text { processes } \\
\text { than before }\end{array}$ & Confirmed \\
\hline $\begin{array}{l}\text { Degree to } \\
\text { which } \\
\text { respondent } \\
\text { feels included } \\
\text { in the meeting }\end{array}$ & 3.61 & 61 & 3.70 & 65 & 0.09 & $6 b:$ & $\begin{array}{l}\text { After the } \\
\text { intervention, } \\
\text { participants } \\
\text { feel more } \\
\text { included } \\
\text { than they did } \\
\text { before }\end{array}$ & Rejected \\
\hline
\end{tabular}

Table $7 \quad$ Other data on meetings, before the intervention phase

\begin{tabular}{lcc}
\hline \multicolumn{1}{c}{ Survey items } & Agency & Bank \\
\hline No. meetings attended per week per respondent & 4.1 & 1.9 \\
Hours spent in meetings per week per respondent & 5.0 & 2.0 \\
Proportion of meeting time wasted, subjectively & $19 \%$ & $17 \%$ \\
\hline
\end{tabular}




\section{Discussion of results}

From a survey of the employees who regularly attended the meetings of the managers that participated in the intervention (the training workshops, the coaching and the redesign of meeting formats), we obtained results that tested six hypotheses about managers' competencies in meeting management and group facilitation.

The hypotheses all compared data before and after the intervention, and their testing thus produced an estimation of the efficacy of the intervention.

Results of the test of Hypothesis 1 (Table 3) confirmed that, as rated by their employees, managers' group-facilitation competencies improved over the course of the intervention. The improvement was small, $0.16^{* * *}$ scale points on the 5-point Likert scale from 1 to 5 . However, considering the modest investment made by the organisations - each manager was away for 1-2 days (a fair number showed up for only one of the two workshops) - as well as the per-day cost for each manager, in the order of US\$1000, a standard price for management development training in Denmark, the intervention may be considered reasonably cost-effective from the point of view of the organisations.

Hypothesis 2 stated that our intention not to train meeting management (agenda use, ensuring results and basic time management) would be reflected in the participating managers not improving these competencies. As it happened (Table 3), there was a small improvement, $0.14 * * *$, so the hypothesis was rejected. A likely explanation for this improvement is that the mere act of raising problems with meetings during the workshops and the coaching reactivated the participating managers' pre-existing and dormant meeting-management competencies and induced them to sharpen up on time management etc. in their meetings.

Hypothesis 3 stated that after the intervention, managers' competencies in the new construct 'meeting facilitation', as measured by the sum of meeting management and group facilitation competencies, would improve. This hypothesis was confirmed (Table 3), with a difference of $0.15^{* * *}$ (this, of course, being the mean of the results of the two previous hypotheses).

Altogether, the intervention produced improvements in meeting facilitation competencies that were statistically highly significant, albeit small in absolute terms, which is what can be expected from a small-scale intervention effort like the present intervention encompassing a few days' worth of brief training, coaching and meeting redesign.

As to the remainder of the hypotheses (numbers 4-6), about more specific matters of meetings and facilitation, we found, in testing Hypothesis 4a, that meeting participants were far less clear about what the discussion about a specific agenda item was meant to accomplish than about the fact that a discussion about a particular topic was to take place. The difference between the two factors, before the intervention, was large, $0.51 * * *$ scale points (Table 4). Measured in terms of numbers of respondents in the 4 and 5 categories (who said they were clear about it to a 'high' or 'particularly high' degree), $60 \%$ of them knew the agenda items, but only $29 \%$ knew what was to be accomplished through the scheduled discussion of them.

This demonstrates the inadequacy of the traditional agenda that simply lists a series of discussion topics, with no direction as to what meeting participants are supposed to do with them. Less than two-thirds of respondents (the 60\%) found that the meetings with 
their manager had an agenda (which is bad enough), but only half of them (the 29\%) had a good sense of what these meetings were generally for. Such a lack of clarity may contribute to the common experience that meetings often flounder; it is also part of the rationale for the group facilitator's concern with providing constant focus and direction during meeting discussions. A meeting manager may think the agenda says it all and that people naturally will want to concentrate on the intended substance, but experience and the results in this research show otherwise.

Our attempts to remedy this situation by training managers to include in the agenda a column of text specifying what the discussion is to accomplish was indeed followed by an increased awareness of what was to be accomplished, in the small amount of $0.14^{* * *}$, or $38 \%$ in the $4+5$ category, up from the $29 \%$ before the intervention. Unfortunately, the gap between those who did know and those who did not remained large and highly significant, down to only 0.45 scale points from the initial 0.51 .

Results from the survey items testing Hypothesis 5a confirm it resoundingly (Table 5): there is a huge difference between being able to cover the entire agenda and wrapping up each agenda item properly: 0.88 scale points or, in terms of categories $4+5: 77 \%$ found their meetings covered the agenda, but only one-third of them, $24 \%$, felt that items were wrapped up properly and conclusions were drawn. Although not included in the training, both factors pick up after the intervention, by small increments, $0.25^{* * *}$ scale points and $0.17^{* * *}$, respectively, such that more meetings have their agendas covered and more items are wrapped up, but the glaring difference between the two is, in fact, widened, from 0.88 to 0.96 , thus confirming our Hypothesis $5 \mathrm{~b}$ that this gap would not be closed.

A very direct test of the extent to which our managers learned group-facilitation competencies was contained in the question, addressed in Hypothesis 6a, about how often meeting participants observed the managers use the various inclusive processes that are the group facilitator's stock in trade, such as silent reflection, buzz dyads, round robins and other small-group discussion platforms. This item scored extremely low preintervention, 2.03 scale points ( $7 \%$ of managers used them often), but picked up by $0.38^{* * *}$ post-intervention, to $15 \%$ of the managers, an improvement that we may call medium-sized (Table 6).

The other part of the hypothesis, $6 \mathrm{~b}$, asked whether such an improvement would lead to an increase in the sense of involvement that meeting participants felt. It did not, the slight change, in the order of +0.1 , was not significant. Since the increased engagement and involvement is the very point of these facilitation processes, this result was, on the face of it, disappointing. However, since the improvement affected only employees of the $8 \%$ of the managers who substantially increased their use of these processes (the $15 \%$ minus the 7\%), we can expect even a large effect on this small group to be drowned out by the data from the remaining $92 \%$ of meeting participants.

As the more specific meeting hypotheses 4-6 show, the managers made some progress on several fronts, often by statistically significant, but substantially small amounts. The intervention failed, however, to close the gaps or inconsistencies observed before the intervention between having an agenda and knowing what to do with it, and between using processes intended to produce involvement and actually obtaining such involvement. 
Our survey included additional data on meeting variables not addressed by the intervention (Table 7). The altogether low number of meetings and hours spent in meetings per week by these employees, amounting to some $5 \%$ of the work week in the (smallish, rural) bank and $10 \%$ in the (larger, highly professionalised) agency, is sobering and somewhat less than modern myth has it.

Further, each respondent indicates that, on the average, he or she experiences about a fifth of the time spent in meetings to be a waste of time. This is again somewhat less than popular anecdote has it, but it corresponds closely to a result reported by Rogelberg et al. (2003, p.5): $17.7 \%$ of 1207 respondents in an internet survey felt their meetings to be 'A fairly bad use of time' or 'A complete waste of time'. Interestingly, similar results have appeared in a number of our other (unreported) investigations, with values ranging narrowly from $17 \%$ to $24 \%$, which suggests that this proportion, about a fifth, may be a psychological construction born from cognitive dissonance as much as from actual experience: 'If I felt it were more, like two-fifths or two-thirds, I would be a fool to suffer such a waste of my time without taking action. So, it is about a fifth'.

\section{Conclusions: improving meetings through facilitation}

The present, theory-driven study is one of very few extant research-based intervention efforts in the domain of organisational meetings. It addresses the challenge of how to change organisational meetings, generally not thought of as objects of change, by focusing on the one person with the most leverage, the leader of the meeting. We conceptualised the meeting leader's competencies in terms of a tension between something old - the mix of authoritarian and parliamentary-democratic styles that have been professionalised into meeting management - and something new and different: the more active, supportive, focus-and-direction-providing approach used by professional process consultants and experts in group facilitation. Supplementing the virtues of the old approach with those of the new, managers can learn a style more appropriate to meetings in today's organisations, which we called meeting facilitation. This was the transformative theory underlying this study.

The brief training provided to the managers from the participating organisations consisted of 1-2 workshops, a coaching session and redesign of 2-3 meeting formats, and it kept each manager busy for about 1-2 workdays. This low-intensity and low-cost intervention produced overall improvements in outcome levels 3 and 4 (change in behaviour and results, Kirkpatrick and Kirkpatrick, 2006) that were highly significant statistically, but small in absolute terms. Paradoxically, although the intervention focused on group-facilitation competencies, meeting-management competencies showed improvements of comparable size, possibly because managers' long-held, but submerged convictions about proper meeting chairmanship reasserted themselves during the facilitation training.

Measurements of individual variables relating to agenda use, discussion follow-ups and participant engagement demonstrated tremendous, previously undocumented inefficiencies associated with the classical meeting management style and thus highlighted the need for radical innovation in the domain of meetings. The brief training in meeting facilitation that was attempted in the present project moves some way towards ameliorating these deficiencies and points to the desirability of larger-scale interventions. 


\section{Acknowledgements}

This research and intervention project reported here was carried out by the author (PI) and two colleagues, Nina Tange and Joan Rokkjær. Assistance from Anders Trolle on the statistical analysis of the data is acknowledged. Funding for this research was provided by one of the participating organisations, Vestjysk Bank, and, for the Danish Ministry of Science, by Statens Center for Kvalitets- og Kompetenceudvikling (the Government Centre for Quality and Competence Development). While HR and other personnel from these organisations helped adapt our proposed training programme to the respective management groups, they played no role in our use of data, concepts or theory.

\section{References}

Baburoglu, O. and Ravn, I. (1992) 'Normative action research', Organization Studies, Vol. 13, No. 1, pp.19-35.

Barab, S. and Squire, K. (2004) 'Design-based research: putting a stake in the ground', The Journal of the Learning Sciences, Vol. 13, No. 1, pp.1-14.

Bens, I. (2002) Facilitating with Ease, Jossey-Bass, San Francisco.

Bostrom, R.P., Anson, R. and Clawson, V.K. (1993) 'Group facilitation and group support systems', in Jessup, L. and Valacich J. (Eds): Group Support Systems: New Perspectives, Macmillan, New York, pp.146-168.

Denyer, D., Tranfield, D. and van Aken, J.E. (2008) 'Developing design propositions through research synthesis', Organization Studies, Vol. 29, pp.393-413.

Doyle, M. and Straus, D. (1976) How to Make Meetings Work, Berkley, New York.

Elsborg, S. and Ravn, I. (2007) Learning Meetings and Conferences in Practice, People's Press, Copenhagen, Denmark.

Freiling, J., Gersch, M. and Goeke, C. (2008) 'On the path towards a competence-based theory of the firm', Organization Studies, Vol. 29, Nos. 8/9, pp.1143-1164.

Garon, J.E. (2002) 'Facilitating meetings', Clinical Leadership and Management Review, Vol. 16, No. 4, pp.215-223.

Heene, A. and Sanchez, R. (1997) Competence-Based Strategic Management, Wiley, New York.

Henkel, S. (2007) Successful Meetings, Atlantic Publishing Company, Florida.

Hogan, C. (2003) Understanding Facilitation: Theory and Principles, Kogan Page, London.

Hogan, C. (2007) Facilitating Multicultural Groups: A Practical Guide, Kogan Page, London.

Hunter, D. (2009) The Art of Facilitation, Wiley, New York.

Kirkpatrick, D.L. and Kirkpatrick, J.D. (2006) Evaluating Training Programs, 3rd ed., BerrettKoehler, San Francisco, CA.

Kristensen, T.S. (2005) 'Intervention studies in occupational epidemiology', Occupational and Environmental Medicine, Vol. 62, pp.205-210.

Mintzberg, H. (1973) The Nature of Managerial Work, Prentice-Hall, Englewood Cliffs, NJ.

Ravn, I. (2005) 'Transformative theory in social research: the case of the learning conference', Presented to Dansk Sociologkongres, Roskilde University, 18-20 August.

Ravn, I. (2011) Facilitation: Ledelse af Møder der Skaber Vaerdi og Mening (Facilitation: Leading Meetings that Create Value and Meaning), Hans Reitzels Forlag, Copenhagen, Denmark. [in Danish]

Ravn, I. (2013) 'A folk theory of meetings - and beyond', European Business Review, Vol. 25, No. 2, pp.163-173. 
Robert, H.M. (1915/2008) Robert's Rules of Order Revised, Wildside Press, Rockville, MD.

Rogelberg, S.G., Allen, J.A., Shanock, L., Scott, C. and Shuffler, M. (2010) 'Employee satisfaction with meetings: a contemporary facet of job satisfaction', Human Resource Management, Vol. 49, No. 2, pp.149-172.

Rogelberg, S.G., Scott, C. and Kello, J. (2007) 'The science and fiction of meetings', Sloan Management Review, Winter, pp.18-21.

Rogelberg, S.G., Warr, P., Leach, D. and Burnfield, J. (2003) Work Meetings: An International Survey-Preliminary Results, Working paper, University of North Carolina.

Rogers, C. R. (1967) 'The interpersonal relationship in the facilitation of learning', in Leeper, T. (Ed.): Humanizing Education, National Education Association, Association for Supervision and Curriculum Development, Washington, pp.1-18.

Romano, N. and Nunamaker, J.F. (2001) 'Meeting analysis: findings from research and practice', Proceedings of the 34th Hawaii International Conference on Systems Sciences, Hawaii, USA.

Schein, E.H. (1988) Process Consultation: Its Role in Organization Development, 2nd ed., Addison-Wesley, Boston, MA.

Schuman, S. (2005) The IAF Handbook of Group Facilitation, Wiley, New York.

Schwarz, R. (1994) The Skilled Facilitator, Jossey-Bass, San Francisco, CA.

Smith, T.E. (2000) Meeting Management, Prentice Hall, Englewood Cliffs, NJ.

Streibel, B. (2002) The Manager's Guide to Effective Meetings, McGraw-Hill, New York.

van Aken, J.E. and Romme, G. (2009) 'Reinventing the future: adding design science to the repertoire of organization and management studies', Organization Management Journal, Vol. 6, pp.5-12.

\section{Notes}

1 Having learned group facilitation during five years as a management consultant in the Danish consulting firms Amphion and Nelleman Konsulenterne prior to joining academia, I trained my colleagues, credited in the acknowledgements, to run the workshops with me, while the first-mentioned colleague, a trained coach, handled most of the coaching. 